\title{
EFFECTS OF TRANSVERSE AIR FLOW ON MASS LOSS RATE OF ALCOHOL POOL FIRES IN AN INCLINED WIND TUNNEL
}

\author{
Changfa TAO, Xishi WANG, Xiaonan ZHANG \\ State Key Lab. of Fire Science, University of Science and Technology of China, \\ JinZhai Road 96, Hefei, 230026 Anhui, China
}

Received 26 Nov 2012; accepted 29 Jan 2013

\begin{abstract}
In order to study the effects of inclined wind direction on combustion characteristics of alcohol pool fires, an inclinable wind tunnel was developed and used for providing venting wind with different directions. The wind tunnel can be sloped from $0^{\circ}$ to $30^{\circ}$ while the fuel pan is kept horizontal inside the tunnel. The wind speed can be altered from 0 to $3.0 \mathrm{~m} / \mathrm{s}$. The mass burning rate of square, rectangular and circular alcohol pool fires under different wind direction have been studied experimentally. The results show that the mass burning rate increases faster with increasing the slope angle of the wind tunnel and increasing the downstream edge length of the pool.
\end{abstract}

Keywords: pool fire, mass burning rate, wind tunnel, wind direction, rectangular.

\section{Introduction}

Concerted efforts have been made on fundamental research to understand the combustion characteristic of pool fires. These efforts concentrated on the establishment of correlations between the fire characteristics, such as mass burning rate, flame height and pulsation soot formation and thermal radiation, and the fuel characteristics, such as fuel type, surface shape and size, and the ambient conditions including pressure, temperature, humidity and wind (Beyler 2008; Heskestad 2008; Tewarson 2008). Building fire can occur at many locations where sloping conditions are expected, such as underground stores, mines and rail or road tunnels. The wind speed and direction, which is controlled by the surface inclination angle, may influence the pool fire combustion characteristics, such as mass burning rate, flame length, flame tilt angle, etc. (Pérez et al. 2010).

Since the 1950s, there has been a huge amount of research on the aspects of pool fires. The mass burning rate of hydrocarbon pool fires with diameters ranging from $0.0037 \mathrm{~m}$ to $22.9 \mathrm{~m}$ has been studied (Blinov, Khudiakov 1961). It was found that the rate of burning expressed as the "fuel surface regression rate" $R_{S}(\mathrm{~mm} / \mathrm{min})$ was high for small-scale laboratory pools $(0.01 \mathrm{~m}$ diameter or smaller). It was found that the burning rates of large aviation fuel pool fires with diameter of $0.6-15 \mathrm{~m}$ decreased with the increase of longitudinal air flow speeds (Apte et al. 1991; Capener, Alger 1972), which was opposite to that of Blinov and Khudiakov (1961). In the transitional and turbulent regime, the mass burning rate was observed to increase with the pool size and can be modeled by an exponential function with an asymptotic limit as the pool size approaches infinity (Babrauskas 1983; Drysdale 1999). Many studies (Apte et al. 1991; Capener, Alger 1972; Carvel et al. 2001; Chatris et al. 2001; Ji et al. 2014; Parkes, Fleischmann 2005; Roh et al. 2007a, b, 2008; Wang, Joulain 2007; Woods et al. $2006 \mathrm{a}, \mathrm{b})$ indicated that the mass burning rate should increase with increasing the air flow speed, where the wind speed on level ground was considered. It was found that the variation of burning rate of these two kinds of pool fires, methanol and gasoline, with air flow speed were definitely different. The burning rate of gasoline pool fire increased monotonously with the air flow speed $(\mathrm{Hu}$ et al. 2009). The experiments were finished in a reduced scale model wind tunnel with a $0.3 \times 0.3 \mathrm{~m}$ cross-section and wind speed from 0.2 to $2 \mathrm{~m} / \mathrm{s}$ (Saito et al. 1995). The burning rates of methanol and n-heptane pool fires with diameter of $0.1-0.25 \mathrm{~m}$ are measured. These results showed that the burning rates of both the two kinds of fuels decreased with increasing wind speed, till to that in an open air. It was reported in a study by Woods et al. (2006) that the burning rate of the a small square pool $(7.5 \times 7.5 \mathrm{~cm})$ showed a monotonic increase by 2.5 times when the air speed rose from 0 to $5.5 \mathrm{~m} / \mathrm{s}$. In contrast, the burning rate of a larger square pool $(30 \times 30 \mathrm{~cm})$ was essentially invariant to this range of air speeds.

The aim of this study is to investigate the effect of wind direction on mass burning rate of alcohol

Corresponding author: Xishi Wang

E-mail:wxs@ustc.edu.cn 
pool fires. The study was conducted in a wind tunnel of variable inclination angle. The control parameters of the experiments include pool size, shape and orientation, as well as the tunnel wind velocity and tunnel inclination angle. The observed and measured parameter was mass of the fuel. The objective of this paper is to contribute to the understanding of liquid alcohol pool fires, with particular attention on how the burning rate is affected by different wind direction. Although many works have been done to study the mass burning rate of pool fires, few experiments involved the variation of wind direction. One question hasn't been solved: how mass burning rate of a pool fire varies under different wind direction relative to the horizontal fuel surface, and how it varies with the pool shape.

\section{Experimental setup and conditions}

\subsection{Fuel and fuel pan}

Alcohol was used in this work as the liquid fuel, $\mathrm{C}_{2} \mathrm{H}_{6} \mathrm{O}$, which produces little soot when combusting under standard atmospheric condition (Woods et al. 2006). It is different from gasoline or other hydrocarbons, since soot radiation is small or nonexistent with alcohol fires. The main factor to influence the thermal transfer is thermal conduction but not thermal radiation for the small pool size $(<10 \mathrm{~cm})$. So, these results could be analysed ignoring the thermal radiation.

Steel fuel pans with different shapes of square, rectangular and circular are used. The size of the square fuel pans are $4 \mathrm{~cm}, 6 \mathrm{~cm}, 8 \mathrm{~cm}$ and $10 \mathrm{~cm}$, respectively. The size of the rectangular pan is $3 \times 12 \mathrm{~cm}$, and the diameter of circular pan is $6.77 \mathrm{~cm}$. All of the pan depth and their wall thickness are $15 \mathrm{~mm}$ and $1 \mathrm{~mm}$, respectively.

\subsection{Experimental apparatus and instrumentation}

The experiments were conducted in a wind tunnel as shown in Figure 1. The slope angle, $\theta$, between the axial direction of the tunnel and the horizontal plane can be altered from $0^{\circ}$ to $30^{\circ}$. The small-scale tunnel is comprised of a $240 \times 42 \times 60 \mathrm{~cm}$ rectangular duct, a $26 \mathrm{~cm}-$ long transition section and a $24 \mathrm{~cm}$-long circular duct of $34 \mathrm{~cm}$ in diameter. The walls of the tunnel are made of decorative high-pressure laminate (HPL) with $0.80 \mathrm{~cm}$ thickness. A $0.75 \mathrm{~kW}$ blow fan was mounted in the circular duct. The fan and the wind tunnel are connected by the transition section. Four layers of $0.8 \mathrm{~cm}$ thick honeycomb were installed immediately trailing rim of the transition section. The gap between each two adjacent layers is $9.2 \mathrm{~cm}$. The velocity range of the tunnel is 0.25 to $3.00 \mathrm{~m} / \mathrm{s}$, the test points is shown in Figure 1 . The turbulence fluctuation intensity of the tunnel flow is less than $6 \%$.

A glass pane of $130 \times 34 \mathrm{~cm}$ was fixed on one side of the wind tunnel as the observation window. A horizontal strut was set in the center of the wind tunnel through the base floor to support the fuel pans. A piece of high-pressure laminate was fixed on the platform with the same area,

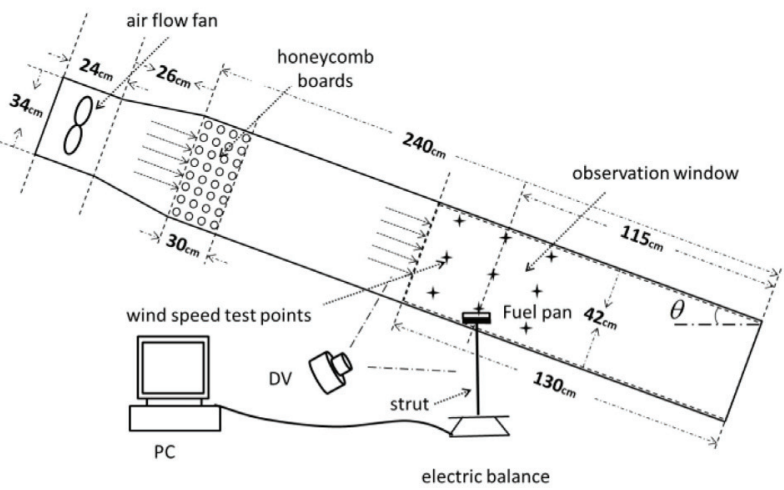

Fig. 1. Schematic diagram of the experimental apparatus

which is heat insulation. An electronic balance was placed under the bottom of the strut to measure the fuel mass variation. The resolution of the electronic balance is $0.01 \mathrm{~g}$. A four-probed parallel processing anemometer with accuracy of $0.01 \mathrm{~m} / \mathrm{s}$ was used to measure the airflow speed in the wind tunnel. The sampling rate of signals from all electronic devices was $1 \mathrm{~Hz}$. A digital video camera was placed approximately $100 \mathrm{~cm}$ from the pool center to record the luminescent flames.

\subsection{Experimental conditions}

For the rectangular fuel pan, two orientations relative to air flow direction were tested. One with the long side axis perpendicular to the tunnel flow direction and the other parallel as shown in Figure 2. The ambient conditions were as followings: the temperature was $20 \pm 2{ }^{\circ} \mathrm{C}$, the ambient pressure was $101 \pm 5 \mathrm{kPa}$ and the ambient humidity was from $10 \%$ to $30 \%$.

\section{Experimental results and discussions}

\subsection{General observation}

Fire is a diffusion controlled combustion process and the burning of liquid fuels is influenced by heat transfer for gasification (Drysdale 1999). The net gain of thermal energy due to radiation and convection feedback from the flame and the surrounding air to the fuel determines the amount of gasified fuel. It participates in the flaming combustion process. As such, the burning rate may undergo significant variations depending on fuel temperature.

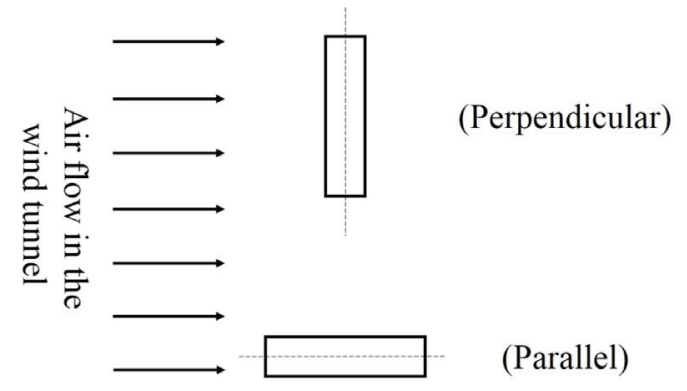

Fig. 2. Plan view of relative positions of the rectangular pan to the tunnel flow direction 


\subsection{Result from square pools with different area under different wind directions}

Presented in Figure 3 are measured time averaged mass loss rates per unit area of the square pool fires under various air flow speeds, slope angles and pan sizes.

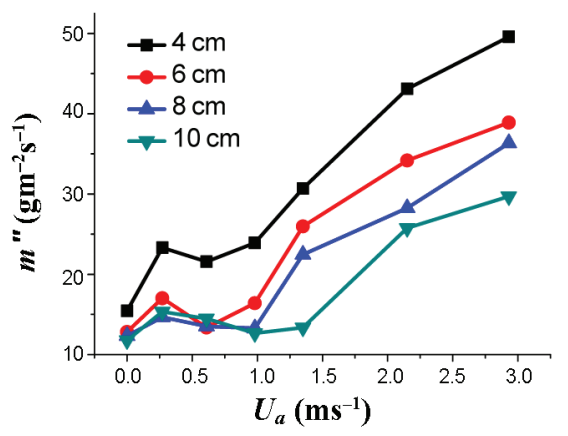

(a) $\theta=0^{\circ}$

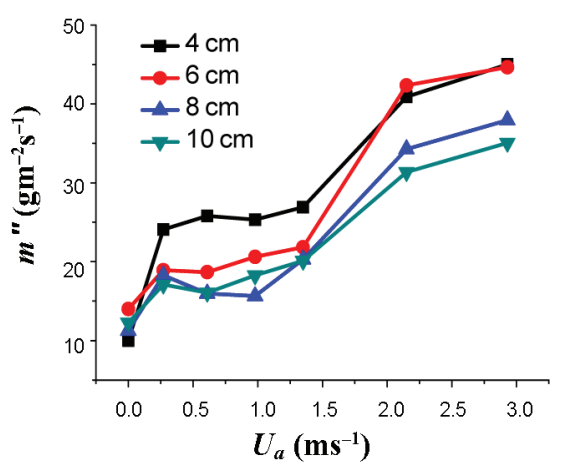

(b) $\theta=10^{\circ}$

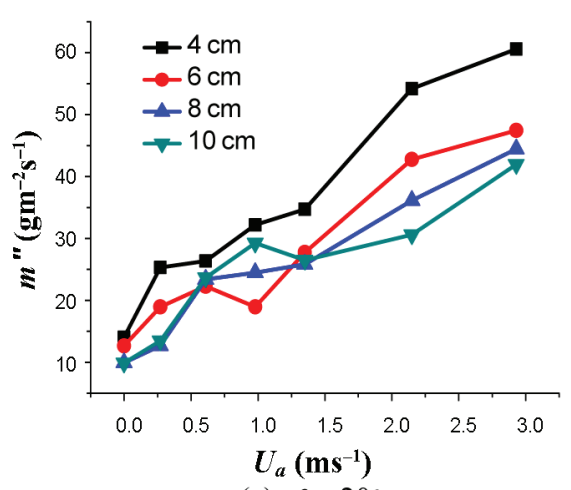

(c) $\theta=20^{\circ}$

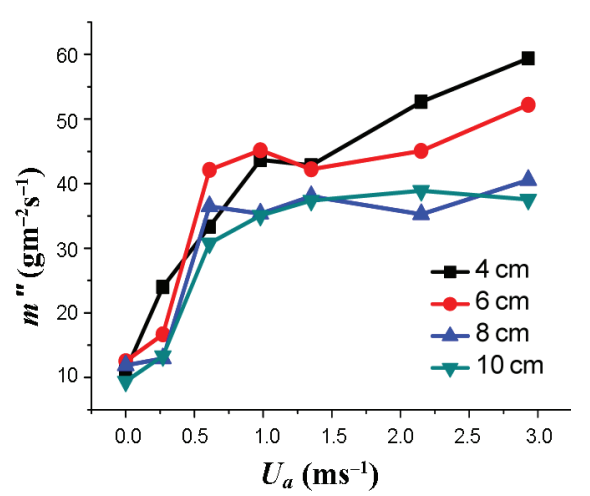

(d) $\theta=30^{\circ}$

Fig. 3. Mass loss rate of square pools under different tunnel angle
The results show that the mass loss rate per unit area decreases with increasing the pool area while the pool size is smaller than $10 \mathrm{~cm}$. For the small size pool, the main factor to influence the mass loss rate is thermal conduction. These results are accorded with the one get by Blinov and Khudiakov (1961). The results also show that the mass loss rate per unit area is proportional to the angle between the wind direction and the fuel surface. The mass loss rate increases fast with increasing the slope angle $\theta$ at the same air flow speed blow $1.5 \mathrm{~m} / \mathrm{s}$, as shown in Figure 3 . It was found that the temperatures of the side and trailing rim walls under longitudinal airflow are much higher than that under a quiescent air condition ( $\mathrm{Hu}$ et al. 2011). The main probable reason the temperature of the downstream edge and parallel-stream edge of pool increased a lot. More heat from the flame is transferred back to the pool rim, which could increase the boiling rate. It is found that the flame exists behind the downstream edge of the pool under the horizontal wind tunnel. On the other hand, the flame exists beside the streamside of the pool under the slope tunnel, as shown in Figure 4, which causes the temperature of streamside of the pool rises. The thermal conduction rate is decided by the sum temperature of pool rims. The higher the general temperature is, the larger the boiling rate is. The boiling rate is the main factor influencing the mass loss rate, so the mass loss rate increases with increasing the general temperature. Therefore, more heat is transferred back to the rim walls while the air flow speed increases, which influences the combustion characteristic of alcohol pool fires.

\section{Results from square, rectangular, and circular pools with equal area}

As shown in Figure 5, the mass loss rate of Rectangler-1 pool fire is the largest, while the circle one is the smallest. The main reason is the downstream edge of Rectangle-1 is longer than others. The longer the rim wall is the more heat could be transferred back to the fuel in pools, which accelerates the boiling rate of the fuel and the combustion rate.

Figure 5 shows that the mass loss rate is proportional to the length of the downstream edge of the pools. L. H. Hu. found that the temperature of the downstream edge of the small pools maybe increases obviously when the wind speed increases, while the temperature of pool streamside increases slightly compared to it under a quiescent air condition (Hu et al. 2011). The horizontal air momentum dominates in the near field of the pools and even for very low air flow speeds the flame is readily pushed over. At higher transverse air flow speeds, the flame was swept back further (Woods et al. 2006). The downstream edge of the pool is heated directly and radiated by flame when the flame body is pushed over. More heat would be transferred by flame under an air flow condition compared to a quiescent air condition. The downstream edge of Rectangler-1 pool is $12 \mathrm{~cm}$, which is heated directly by the flame, and the tempera- 

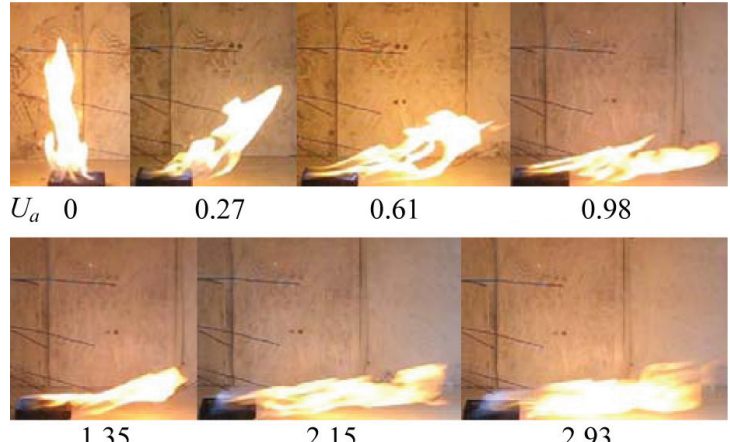

(a) $\theta=0^{\circ}$
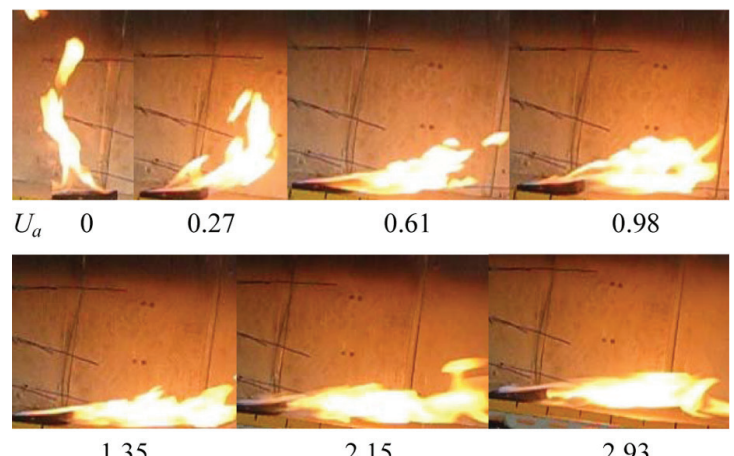

(b) $\theta=10^{\circ}$
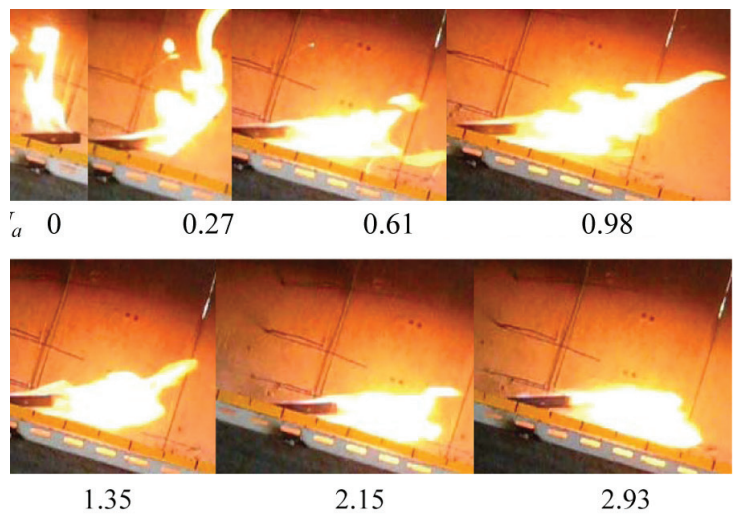

(c) $\theta=20^{\circ}$
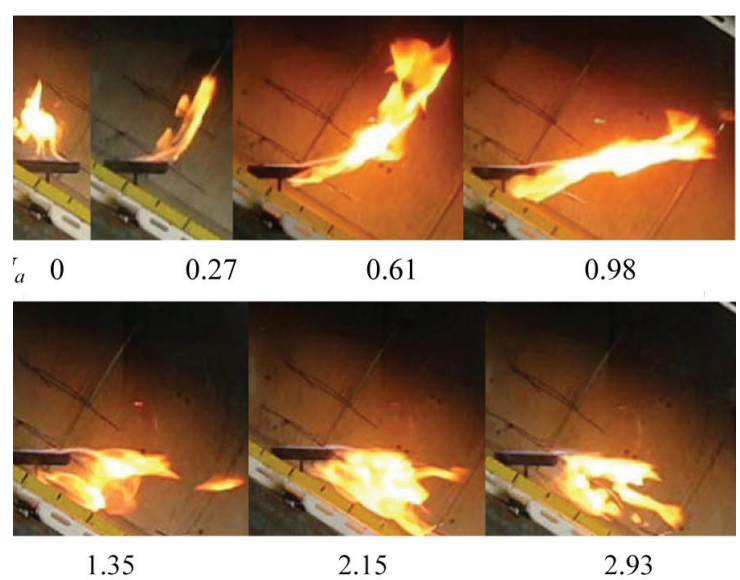

(d) $\theta=30^{\circ}$

Fig. 4. Stretching of flames of square pool fire at $10 \mathrm{~cm}$ under different degree lean

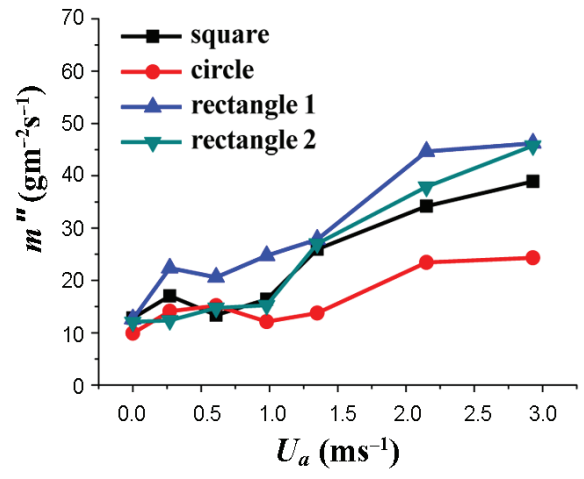

a) $\theta=0^{\circ}$

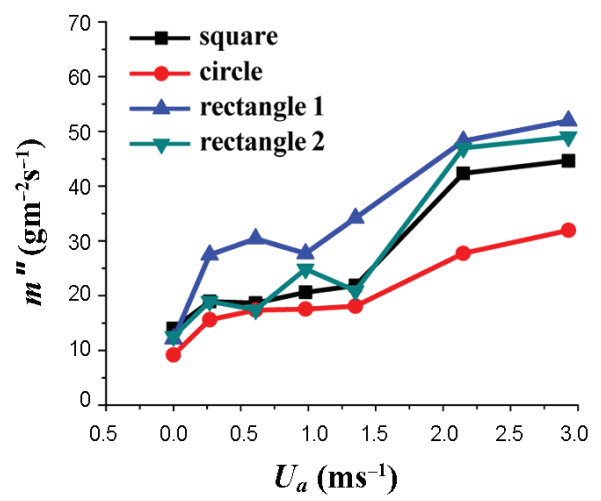

b) $\theta=10^{\circ}$

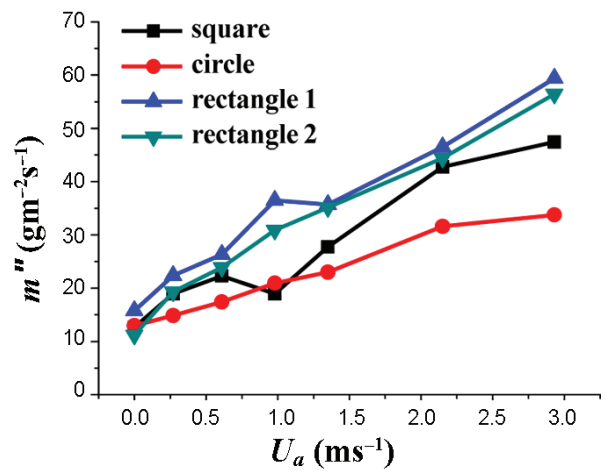

c) $\theta=20^{\circ}$

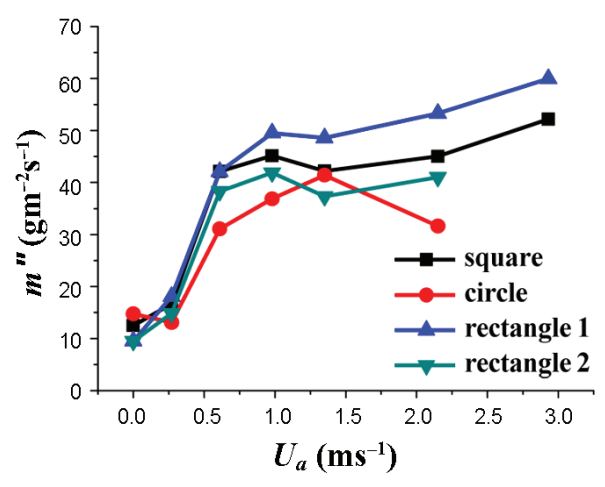

d) $\theta=30^{\circ}$

Fig. 5. Mass loss rate of different shape pools under different tunnel angle 
ture of it would be the highest one of four pool rims, both as the one of Rectangler-2, which is only $3 \mathrm{~cm}$. The temperature of the streamside of the rectangular pool increases under slope wind tunnel. A small part of flame exists beside the streamside of pool which increases the temperature of it. But the temperature of streamside increases not as much as the one of the downstream edge since the flame concentrates behind the trailing edge. The main factor influencing the general temperature of pool rims is the length of trailing rim. For the circular pool, the equivalent length of trailing rim is difficult to decide its variation under different air flow speeds.

\section{Conclusions}

The mass loss rate is proportional to the angle between the wind direction and the fuel surface. It increases faster with increasing the slope angle with wind speed below about $1.5 \mathrm{~m} / \mathrm{s}$. This is because more heat feedback to the downstream edge of the pool. Moreover, the mass loss rate is proportional to the length of the downstream edge wall of the pool, because the trailing of the pool is heated directly by flame, and more heat is transferred under air flow condition in comparison to the case in quiescent air condition. The longer the rim wall is, the more heat could be transferred to the fuel in the pool, which can accelerate the boiling rate of the fuel and the mass loss rate. So the mass loss rate of rectangular-1 pool $(3 \times 12 \mathrm{~cm})$ is the largest and the circular pool (diameter $6.77 \mathrm{~cm}$ ) one is the smallest all of them.

\section{Acknowledgment}

The authors appreciate the support of the China National Key Basic Research Special Funds project (Grant No. 2012CB719704) and the National Key Technology R\&D Program (Grant No. 2011BAK03B02).

\section{References}

Apte, V. B.; Green, A. R.; Kent, J. H. 1991. Pool fire plume flow in a large-scale wind tunnel, in Proceedings of the $3^{\text {rd }}$ Symposium (Int.) on Fire Safety Science, 8-12 July 1991, Edinburgh, UK, 425-434.

Babrauskas, V. 1983. Estimating large pool fire burning rates, Fire Technology 19(4): 251-261. http://dx.doi.org/10.1007/BF02380810

Beyler, C. L. 2008. Fire hazard calculations for large, open hydrocarbon fires, in SFPE Handbook of Fire Protection Engineering. Quincy, Massachusetts: National Fire Protection Association, 3.271-3.319.

Blinov, V. I.; Khudiakov, G. N. 1961. Diffusion burning of liquids. U.S. Army Translation, NTIS.

Capener, E. L.; Alger, R. S. 1972. Characterization and suppression of aircraft. Fuel fires. Western States Section, The Combustion Institute, WSCI 72-76, Monterey, CA, $72-76$.

Carvel, R. O.; Beard, A. N.; Jowitt, P. W. 2001. The influence of longitudinal ventilation systems on fires in tunnels, Tunnelling and Underground Space Technology 16(1): 3-21. http://dx.doi.org/10.1016/S0886-7798(01)00025-6
Chatris, J. M.; Quintela, J.; Folch, J.; Planas, E.; Arnaldos, J.; Casal, J. 2001. Experimental study of burning rate in hydrocarbon pool fires, Combustion and Flame 126(1-2): 13731383. http://dx.doi.org/10.1016/S0010-2180(01)00262-0

Drysdale, D. D. 1999. An introduction to fire dynamics. $2^{\text {nd }}$ ed. Philadelphia: John Wiley \& Sons, 31-35.

Heskestad, G. 2008. Fire plumes, flame height and air entrainment, in SFPE Handbook of Fire Protection Engineering. Boston, Massachusetts: Society of Fire Protection Engineers, 2.1-2.20.

Hu, L. H.; Liu, S.; Peng, W.; Huo, R. 2009. Experimental study on burning rates of square/rectangular gasoline and methanol pool fires under longitudinal air flow in a wind tunnel, Journal of Hazardous Materials 169(1-3): 972-979. http://dx.doi.org/10.1016/j.jhazmat.2009.04.050

Hu, L. H.; Liu, S.; Xu, Y.; Li, D. 2011. A wind tunnel experimental study on burning rate enhancement behavior of gasoline pool fires by cross air flow, Combustion and Flame 158(3): 586-591. http://dx.doi.org/10.1016/j.combustflame.2010.10.013

Ji, J.; Fan, C. G.; Gao, Z. H.; Sun, J. H. 2014. Effects of vertical shaft geometry on natural ventilation in urban road tunnel fires, Journal of Civil Engineering and Management 20(4): 466-476. http://dx.doi.org/10.3846/13923730.2013.801916

Parkes, A. R.; Fleischmann, C. M. 2005. The impact of location and ventilation on pool fires in a compartment, in Proc. $8^{\text {th }}$ International Symposium on Fire Safety Science, 18-23 September 2005, Beijing, China, 1289-1300.

Pérez, Y.; Pastor, E.; Agueda, A.; Planas, E. 2010. Effect of wind and slope when scaling the forest fires rate of spread of laboratory experiments, Fire Technology 47(2): 475-489. http://dx.doi.org/10.1007/s10694-010-0168-7

Roh, J.; Ryou, H.; Kim, D.; Jung, W.; Jang, Y. 2007a. Critical velocity and burning rate in pool fire during longitudinal ventilation, Tunnelling and Underground Space Technology 22(3): 262-271. http://dx.doi.org/10.1016/j.tust.2006.08.003

Roh, J.; Yang, S.; Ryou, H. 2007b. Tunnel fires: experiments on critical velocity and burning rate in pool fire during longitudinal ventilation, Journal of Fire Science 25(2): 161-176. http://dx.doi.org/10.1177/0734904107067300

Roh, J.; Yang, S.; Ryou, H.; Yoon, M.; Jeong, Y. 2008. An experimental study on the effect of ventilation velocity on burning rate in tunnel fires - heptane pool fire case, Building and Environment 43(7): 1225-1231. http://dx.doi.org/10.1016/j.buildenv.2007.03.007

Saito, N.; Yamada, T.; Sekizawa, A.; Yanai, E.; Watanabe, Y.; Miyazaki, A. 1995. Experimental study on fire behavior in a wind tunnel with a reduced scale model, in Proceedings of the $2^{\text {nd }}$ International Conference on Safety in Road and Rail Tunnels, 3-6 April 1995, Granada, Spain, 303-310.

Tewarson, A. 2008. Generation of heat and gaseous, liquid, and solid products in fires, in SFPE Handbook of Fire Protection Engineering. Boston: Society of Fire Protection Engineers, 3.109-3.194.

Wang, H.; Joulain, P. 2007. Numerical simulation of windaided flame propagation over horizontal surface of liquid fuel in a model tunnel, Journal of Loss Prevention in the Process Industries 20(4-6): 541-550. http://dx.doi.org/10.1016/j.jlp.2007.04.002

Woods, J.; Fleck, B.; Kostiuk, L. 2006a. Effects of transverse air flow on burning rates of rectangular methanol pool fires, Combustion and Flame 146(1-2): 379-390. http://dx.doi.org/10.1016/j.combustflame.2006.02.007

Woods, A. R.; Fleck, B. A.; Kostiuk, L. W. 2006b. Effects of transverse air flow on burning rates of rectangular methanol pool fires, Combustion and Flame 146(1-2): 379-390. http://dx.doi.org/10.1016/j.combustflame.2006.02.007 
Changfa TAO. He received his Bachelor's degree in 2007 from the Department of Physics, Ludong University. He is currently a $\mathrm{PhD}$ candidate of the State Key Lab. of Fire Science, University of Science and Technology of China. His research interests include combustion characteristic of pool fires and fire suppression mechanisms with water mist.

Xishi WANG. He received his MSc degree in 1997 from Anhui Institute of Optic \& Fine Mechanics of Chinese Academia Sinica and his PhD in 2002 from University of Science \& Technology of China. At the end of 2002, he worked at the Department of Chemical System Engineering of the University of Tokyo for 3 months as a Visiting Scholar. During 2003 to 2005, he worked as a Postdoctor at the Department of Mechanical Engineering of the Hong Kong University of Science \& Technology. He also worked as a Visiting Scholar for two months at the Hong Kong Polytechnic University in 2009. He is currently an Associate Professor of the State Key Lab. of Fire Science, University of Science \& Technology of China. His research focus on fire suppression mechanisms and technologies, laser based diagnostic methods for flame related two/multi-phase flows, etc.

Xiaonan ZHANG. She received her Bachelor's degree in 2009 from North China University of Water Resources and Electric Power and her Master Degree in 2012 from the State Key Lab. of Fire Science, University of Science \& Technology of China, respectively. Her research interests focus on fire suppression and fire smoke control. 